\title{
ESTRATÉGIAS DE MARKETING DE CONTEÚDO PARA PEQUENAS EMPRESAS
}

\author{
Daniele Kelmy Silva LEAL ${ }^{1}$ \\ Luiz Antonio de Carvalho GODINHO² \\ Maria Eugênia Monteiro CASTANHEIRA ${ }^{3}$
}

\begin{abstract}
${ }^{1}$ Graduada do Curso de Administração, Centro Universitário Newton Paiva, Belo Horizonte/MG danielekelmy@gmail.com.br

${ }^{2}$ Doutor em Administração pela UFMG, Centro Universitário Newton Paiva, Belo Horizonte/MG, luiz.godinho@newtonpaiva.br

${ }^{3}$ Professora de metodologia, Centro Universitário Newton Paiva, Belo Horizonte/MG maria.monteiro@ newtonpaiva.br.
\end{abstract}

Recebido em: 10/11/2017 - Aprovado em: 10/12/2017 - Disponibilizado em: 30/12/2017

\begin{abstract}
RESUMO
O presente artigo visa analisar a importância das estratégias de marketing de conteúdo na gestão mercadológica de uma pequena empresa. Portanto, esse estudo tem por objetivo geral avaliar os efeitos que a adoção das estratégias do marketing de conteúdo pode gerar para a organização. Os objetivos específicos irá traçar o perfil de cliente ideal para a empresa, analisar formatos e canais de distribuição de conteúdos de acordo com o perfil de sua persona e os propósitos da organização, por fim traçar as metas que se pretende alcançar.A metodologia desse artigo quanto aos fins foi aplicada propondo à empresa a adoção das estratégias do marketing de conteúdo para sanar as dificuldades identificadas que foram a falta de recursos financeiros para fazer publicidade em mídias tradicionais, atrair mais pessoas com interesse em seu negócio e quais os tipos de conteúdos produzir para expandir a sua marca de forma autêntica no mercado. Quanto aos meios, a pesquisa foi de campo para coletar informações da empresa e de seus clientes através de questionários e entrevistas. Portanto, observou-se que a empresa possui algumas práticas de marketing digital, porém insuficientes para aumentar as oportunidades de negócios com uma audiência que atualmente está em busca por uma publicidade verdadeira, mais afetiva e que faça sentido.
\end{abstract}

Palavras-chave:Marketing de Conteúdo. Marketing Digital.Inboud Marketing.Funil de conversão.Leads.

\begin{abstract}
This article aims to analyze the importance of content marketing strategies in the marketing management of a small company. Therefore, this study has as a general objective to evaluate the effects that the adoption of content marketing strategies can generate for the organization. The specific objectives will outline the ideal client profile for the company, analyze formats and content distribution channels according to the profile of its persona and the purposes of the organization, in order to outline the goals that are to be achieved. The methodology of this article about the ends was applied proposing to the company the adoption of content marketing strategies to remedy the identified difficulties that were the lack of financial resources to advertise in traditional media, to attract more people with interest in their business and what the Content types produce to expand your brand in an authentic way in the market. As for the means, the field research was to collect information from the company and its clients through questionnaires and interviews. Therefore, it was noted that the company has some digital marketing practices, but insufficient to increase business opportunities with an audience that is currently looking for true, more affective and meaningful advertising.
\end{abstract}

Keywords: Content Marketing. Digital marketing.Inboud Marketing. Conversion funnel.Leads. 


\section{INTRODUÇÃO}

Atualmente o mundo mudou, o marketing mudou, ou melhor, evoluiu e muito tem se discutido sobre essa transformação. Vivemos hoje a era digital em que a conectividade está presente na vida das pessoas e alterando o seu comportamento para fazer negócios.

A organização foco de estudo é a"Pé na Trilha Adventure", fundada em 2015, o seu ramo de sua atividade é o ecoturismo e turismo de aventura.A relação existente entre a unidade de análise e o tema abordado é de alta relevância para que a organização trace estratégias de marketing de conteúdo digital para criar vínculos colossais com seu públicoalvo, expandir sua marca e aumentar suas vendas. $\mathrm{O}$ posicionamento da empresa está na fase de introdução mercadológica, ou seja, fase de criação da notoriedade de sua brand no mercado. A organização em análise precisa adotar as práticas do marketing de conteúdo para gerar uma conexão subjetiva de envolvimento com seu público-alvo para que então a sua marca seja construída e consolidada na mente de seus consumidores. Avalia-se então que a criação de conteúdo relevante proporciona a empresa a criar sua própria personalidade mercadológica, sendo autêntica, a fim de educar, inspirar e entreter seu consumidor e, por consequência gerar maiores índices de conversão de clientes a baixo custo quase que espontaneamente e aliados de sua marca.
Através das estratégias do marketing de conteúdo, qual será o impacto gerado para a organização?

O objetivo geral desse estudo visa avaliar os efeitos que a adoção das estratégias de marketing de conteúdo pode gerar para a organização. Portanto os objetivos específicos são:

a) identificar quais são as ansiedades e desejos do público alvo, traçar seu perfil e sua persona;

b) estudar metas e o planejamento de conteúdos digitais;

c) verificar formatos e mix de conteúdos autênticos e analisar os principais canais de distribuição digital.

A produção de marketing de conteúdo irá ajudar a organização a conquistar seu consumidor que passará por um processo de transformação até se tornar parceiro da marca. De acordo com Kotler (2017), o marketing de conteúdo muda a visão do consumidor com a marca da empresa, logo, a Pé na Trilha adventure criará conexões de valor com seus clientes e potenciais leads alcançando o reconhecimento de sua marca e aumentando seu posicionamento no mercado.

\section{REFERENCIAL TEÓRICO}

\section{O marketing na era digital}

Conforme definição de Peçanha (2014), o marketing digital é o conjunto de atividades que uma empresa (ou pessoa) executa online com o objetivo de atrair novos 
negócios, criar relacionamentos e desenvolver uma identidade de marca. Dentre as suas principais estratégias estão o SEO, Inbound Marketing e o Marketing de Conteúdo.

De acordo com a autora, verifica-se que para a organização tornar-se digital é necessário apropriar das estratégias digitais em função dos objetivos da marca e estar presente nas diversas formas digitais estreitando o relacionamento com seu público-alvo.

É óbvio que a web não resolverá todos os problemas de marketing de uma empresa, nem veio para suplantar todas as outras mídias. Por isso, a palavra-chave não érevolução, e sim evolução. O que a Internet trouxe de mais inovador foi o fato de ter mudado o comportamento das pessoas, tirando-as da passividade e tornando -as mais crí ticas, exigentes e com voz ativa. (TURCHI, 2012, 64).

Para Kotler (2017), na economia digital, os clientes estão socialmente conectados em redes horizontais de comunidades, que hoje são os novos segmentos, diante disso, a empresa deverá pedir permissão, precisam agir como parceiros dotados de um desejo sincero de ajudar desde que se tornem transparentes e não caçadores com uma isca.

\section{Inbound Marketing}

Segundo Borges, (2013) uma nova tendência, um novo estilo de se fazer marketing está mudando as regras do jogo, empurrar a venda para o potencial cliente já não faz mais sentido para esse novo conceito de geração de vendas. Um novo conceitoque tem por objetivo a entrega de valor no relacionamento de comprado cliente até que se torne um defensor da marca.

\section{Conforme Kawasaki (2016, APUD} REZ, p.227)“'Se você tem mais dinheiro que cérebro, deve focar em marketing de interrupção. Se tem mais cérebro que dinheiro, deve focar em Inbound Marketing".

O Inbound Marketing é
uma forma de divulgação
baseada na ideia de criação
de conteúdo de qualidade
para um público específico
e veiculação por
ferramentas de Marketing
Digital para atrair o
público-alvo, construir um
relacionamento que poderá
levá-lo até a experiência de
venda. (ASSAD, 2016, p
9)

Todo o processo de inboundmarkting consiste em atrair o público por blogs, redes sociais, técnicas de SEO, converter utilizando Calls-to-action em landing pages, preenchendo formulários, email marketing, organização de contatos em lead scoring, integrar com o CRM e nutrir o relacionamento pelas redes sociais até conquistar o cliente. Entende-se que as etapas desse processo formam o que podemos chamar de metamorfose de conversão que é alimentado por conteúdo relevante e subjetivo para atrair o potencial consumidor envolvendo-o de uma maneira diferenciada a 
cada nível do processo. Em seu último nível de transformação, o cliente transfigura-se num embaixador da marca sendo lucrativo por um longo período de tempo. (ASSAD, 2016; BORGES, 2013).

FIGURA 1 - O processo de Inboud Marketing

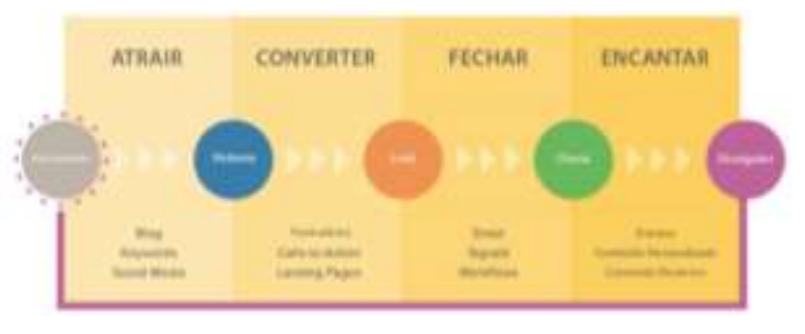

Fonte: Rock Content/Inbound Marketing 2.0

"Ao utilizar Inbound Marketing as empresas conseguem gerar 54\% mais leads (oportunidades de negócio), [...] Assim, normalmente quando se usa Inbound Marketing cada lead custa $61 \%$ a menos." (BORGES, 2013, p.9)

\section{O que é marketing de conteúdo}

De acordo com o Content Marketing Institute, (apud RENZ, 2016, p.2) “O marketing de conteúdo é uma técnica que cria e distribui conteúdo de valor, relevante e consistente, para atrair e engajar uma audiência claramente definida, com o objetivo de encaminhar o cliente a tomar alguma ação que gere lucro".

Para Keith (APUD RENZ, 2016, p 2), marketing de conteúdo é o oposto de anúncio, e isso significa engajar os clientes com um conteúdo que eles realmente desejam, de uma

forma que sirva aos propósitos e aos ideais da marca, ao invés de apenas tentar incluir o logotipo no campo visual.

"Marketing de conteúdo é uma abordagem que envolve criar, selecionar, distribuir e ampliar conteúdo que seja interessante, relevante e útil para um público claramente definido com o objetivo de gerar conversas sobre conteúdo." (KOTLER, 2017, p.147).

Para Kotler (2017), o marketing de conteúdo é o futuro da publicidade na economia digital, pois a transparência e a conectividade na internet permite aos consumidores a conversar e descobrir a verdade sobre as marcas, uma vez que o marketing tradicional perdeu toda a sua credibilidade fazendo com que os consumidores perdessem toda a confiança em propagandas intrusivas, apenas com discurso de venda sem geração de valor, irrelevantes e descartáveis. A confiança desses consumidores estão em indicações da família e amigos de sua comunidade, o que entendese ser a chamada economia compartilhada.

No passado, os
consumidores ouviam com
atenção a transmissão de
conteúdos pela mídia
tradicional, inclusive a
publicidade.
simplesmente não tinham
escolha. A mídia social
mudou isso. Agora, os
consumidores têm a
disposição um grande
volume de conteúdo
gerado por outros usuários,
o qual eles consideram 
mais confiável e bem mais atraente do que aquele oferecido pela mídia tradicional. (KOTLER, 2017, p.148).

Kotler (2017), demonstra o passo a passo do marketing de conteúdo que por natureza envolve produção e distribuição de conteúdo original ou de fontes externas que geram credibilidade, autenticidade e confiança na relação entre o consumidor e a marca.

Afirma também, que a distribuição do conteúdo deverá ser feita pelo melhor mix de canais adequadas à empresa e não cair na armadilha de não definir uma estratégia de marketing de conteúdo, pois apenas produzir e distribuir conteúdo sem planejamento é um caminho muito arriscado. É preciso realizar todas as oito atividades certas, começando pela fixação de metas que tem como princípio estabeler objetivos, onde se quer chegar com uma campanha de marketing. É preciso realizar o mapeamento da persona, selecionar ideias e temas, criar o conteúdo em si, pensar na logística do conteúdo, na ampliação do conteúdo e por fim, avaliar e melhorar tais estratégias.

Rez (2016), aborda que o marketing de conteúdo deverá ser certo, para a pessoa certa no momento certo. Os clientes passam por várias etapas até tomarem a decisão de compra, tais etapas é chamado de funil de conversão.
O funil de conversão é o caminho dentro do site por onde os clientes potenciais passam. Como o nome sugere, no fim, o resultado é uma conversão. O número de tráfego (visitantes)que o site recebe é maior do que a quantidade que converte no final (compradores). Por isso o formato de um funil. [...]. O processo é específico e dá ênfase no comportamento do cliente, na nutrição do relacionamento com ele e na manutenção e retenção deste lead em cada etapa do processo. (KOTLER, 2017, p.157).

Segundo Pullizi (2016), a empresa precisa de vendarketing. um processo que combine o seu processo interno de vendas com o processo de compra de seu cliente, desenvolver um ciclo de envolvimento que definirá qual será o processo que o público alvo passará enquanto a empresa o ajuda a cada vez mais se envolver com sua marca.

FIGURA 2 - Demonstração do Processo funil de Conversão.

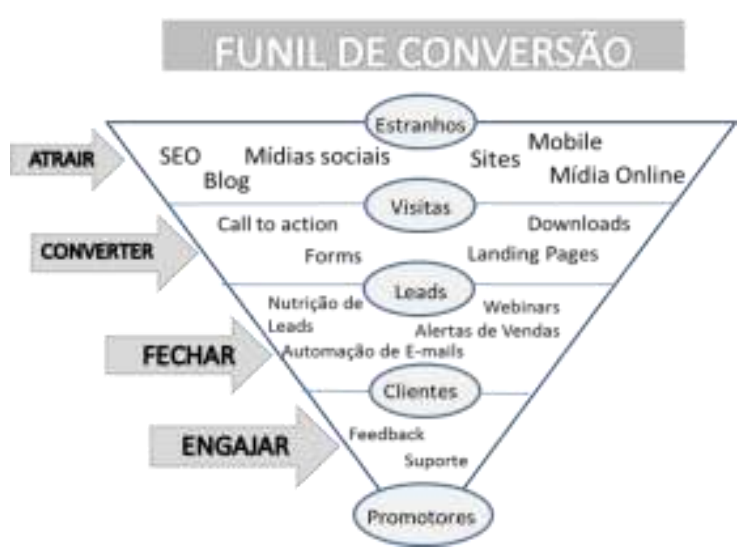

Fonte: Marketing de Conteúdo - A moeda do século XXI -2017. Adaptada pelo autor. 
Ferramentas

para

trabalhar

com

marketing de conteúdo

Conforme Rez (2017), existem

ferramentas para encontrar as preferências de conteúdos que estão em alta na internet, ferramentas para produção de conteúdos, ferramentas para mensurar resultados e por fim, ferramentas de logística para facilitar a distribuição do conteúdo de forma assertiva.

Segundo Peçanha (2017), As ferramentas para coleta de dados para traçar a persona, são questionários online para realizar uma pesquisa de mercado, podendo utilizar o google formuários, por exemplo. Fazer o uso da ferramenta google analytics para extrair e interpretar informações de uma audiência. Há também o facebook para negócios que detém de informações úteis e até mais verdadeiras.

Peçanha (2017) diz, para a construção de um blog a melhor ferramenta é o wordpress que não demanda habilidades técnicas para sua utilização. Há também as redes sociais que servem de canal de distribuição, tais como o facebook, instagram, youtube, pinterest, linkedln, Twitter, email marketing, websites, Snapchat,webinários, dentre outros.

Por fim, Peçanha (2017) fala que para facilitar a gestão de todas as tarefas, existe alguns softwares que fazem automação de marketing que aumentam exponencialmente a eficiência do marketing.

\section{Mundanças de poder para os consumidores} conectados

“A estrutura de poder está passando por mudanças drásticas. A internet, que trouxe conectividade e transparência às nossas vidas, tem sido em grande parte responsável por essas transformações.” (KOTLER, 2017, p.20.).

Estamos testemunhado
também como uma
estrutura de poder vertical
tem sido diluída por uma
força mais horizontal.
Vemos, por exemplo,
como no topo dos países
mais populosos do mundo
estão os "Estados Unidos
do Facebook", com sua
população de 1,65 bilhao
de pessoas. Até o Youtube
pegou Hollywood de
surpresa com seu sucesso
repentino.(KOTLER,
2017, p.20/21).

Segundo Kotler (2017), a força social tem se mostrado cada vez mais poderosameio às grandes potências verticais, exclusivas e individuais. A nova realidade cria uma nação globalizada em um campo de jogo nivelado em que comunidades se conectam rumo à economia compartilhada de inclusão social. O individualismo tornou-se uma ação obsoleta, dando lugar ao cooperativismo, cocriação, conexão e desenvolvimento em que o mercado fornece as ideias e as empresas vendem essas ideias.

\section{METODOLOGIA}

Quanto aos fins, a pesquisa utilizada foiaplicada, pois segundo Vergara (2016, 
p.42)está associada a "necessidade de resolver problemas concretos, mais imediatos, ou não. Tem, portanto, finalidade prática”.A pesquisa propôs o uso das práticas de marketing de conteúdo digital para aumentar o número de interessados em seu negócio a fim de converter esse público em clientes e ampliar o reconhecimento de sua marca, como consequência oaumento das vendas da empresa.

Quanto aos meios, a pesquisa foi de campo porque, segundo Vergara (2016, p.43),a "Pesquisa de campo é investigação empírica realizada no local onde ocorre ou ocorreu um fenômeno ou que dispõe de elementos para explicá-lo. Pode incluir entrevistas, aplicação de questionários, testes e observação participante ou não.”. Dessa forma, realizou-seo mapeamento de personas, essemapeamentofoi feito através da aplicação de um questionárioonline construído no site formulários googlecom perguntas abertas e fechadas a fim de entender qual é o perfil de cliente ideal para a organização e assim poder gerar conteúdos relevantes, específicos e de total interesse desse público. As pessoas que responderam esse questionário foram os próprios clientes da empresa.Para complementar o mapeamento da persona ideal, foram extraídos dados do público alvo no gerenciador de negócios da página do facebook da organização para verificar os dados demográficos e comportamentais de sua audiência.Foi feita uma entrevista com perguntas abertas e informal com o gestor da empresa para coletar informações de como é feito o marketing da Pé na Trilha e verificar os principais objetivos da organização. Todo o embasamento teórico foi construído através de pesquisa bibliográfica sob informações retiradas de várias obras com autores experts do tema.

Os instrumentos de coleta foram:

a) entrevista com o gestor;

b) questionário online para definição de personas;

c) facebook para negócios.

\section{RESULTADOS E DISCUSSÃO}

Conforme Kotler (2017) afirma, as estratégias de marketing de conteúdo envolve todo um planejamento de ações para que o marketing de conteúdo seja eficaz dentro de uma organização.

Sob esse contexto é que as estratégias de marketing de conteúdo propostas à empresa Pé na Trilha Adventure foram esquematizadas.Verifica-se que a organização possui algumas deficiências mercadológicas, uma vez que, as oportunidades de geração de negócios são relativamente baixas devido à sua marca ter pouca visibilidade em seu mercado, ocasionando vendas abaixo das expectativas da companhia. Observa-se também que uma das principais dificuldades da empresa em expandir a sua marca é a questão da falta de verba para investir em marketing de mídias tradicionais que são tão dispendiosas.Atualmente a organização conta com a publicidade digital, possuindo um site 
corporativo e presença nas principais redes sociais que são o facebook, instagram e o youtube, porém as ações realizadas estão sendo insuficientes para atrair o público alvo e gerar mais vendas.

Diante disso, foram traçados juntamente com o gestor geral da empresa os principais objetivos estratégicos essenciais para a implantação do marketing de conteúdo na empresa os quais seguem abaixo:

a) aumentar o reconhecimento de sua marca;

b) gerar oportunidades de negócios;

c) reduzir custos.

Definidos os objetivos estratégicos do marketing de conteúdo, o próximo passo foi construir uma representação de cliente ideal para que a empresa possa personalizar a sua comunicação.

Através do questionário de definição de personas e análise da página do facebook para negócios da empresa, identificou-se que o público alvo consiste em $79 \%$ ser do sexo feminino enquanto que $11 \%$ do sexo masculino. O questionário online foi elaborado e enviado para os 1200 clientes da empresa via whatsapp, contendo sete perguntas fechadas e oito abertas, contou com a participação efetiva de 62 respondentes que já usufruíram dos serviços da empresa. Após análise dos resultados da pesquisa feita através de um questionário online, foi possível construir um perfil de cliente ideal para a empresa, apresentando os principais interesses, objetivos e problemas do cliente ideal em busca de compreender a persona e construir conteúdos mais direcionados e com maiores chances de engajamento.

\section{FIGURA 3 - Representação do cliente ideal para a} empresa Pé na Trilha.

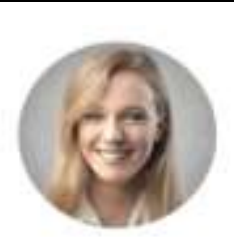

Aline Queiroz

\section{Gestora Financeira}

Histórico:Alinereside em $\mathrm{BH}, \quad$ trabalhana Seniorsoluction, uma empresa de 200 funcionários focada em tecnologia para instituições financeiras. Sua principal função é cuidar do departamento de finanças da empresa, lidando com muitos problemas diariamente.

Idade: 24 anos. Gênero: Feminino.

Educação: Ensino Superior.

Mídias: as principais mídias sociais favoritas são o instagram, facebook e youtube. Usa ativamente o google, blogs e sitesem busca de informações para sanar dúvidas e problemas.

Objetivos:busca por estabilidade e qualidade de vida, gosta de viajar e curtir novas experiências com os amigos.Sempre procura sair da rotina conhecendo lugares incomuns a um custo benefício que esteja pautado na segurança econforto. Precisa de uma válvula de escape para fugir dos problemas diários.Interesses: Viajar, correr, séries e filmes, nadar, passear com família e amigos, música, internet, festas, bares, teatros, fazer compras, livros e ficar em casa.Desafios:Muito stress do trabalho, pouco tempo para fazer o que gosta.Dificuldades de encontrar opções interessantes que sirvam de refúgio dos problemas do dia a dia.

Como a Pé na Trilha pode ajuda-la:Assegurar conteúdos que estimularão Aline a cuidar mais de si, a ter uma vida saudável através das atividades típicas do 
ecoturismo e turismo de aventura. Gerar autoridade sobre passeios em meio à natureza com segurança, conforto e tranquilidade, oferecer um mix diversificado de roteiros diferenciados a um custo benefício pautados pela qualidade e confiança.

Fonte: Criado pelo próprio autor utilizando a ferramenta gerador de personas da Rockcontent

No entanto, o próximo passo foi a escolha dos canais de distribuição e os formatos dos conteúdos baseados nos objetivos das estratégias de conteúdo e no perfil da persona ideal. Diante disso, foram propostos o instagram, facebook, youtube blog, e-mail marketing e whatsapp como canais de distribuição, quantos aos formatos a sugestão é a criação de conteúdos que não percam valor diante do tempo. Conteúdos que não possuem data de validade, como por exemplo, um ebook com os 10 melhores lugares de Minas Gerais para se visitar.Sob a análise do marketing da empresa, foi observado que a mesma não possui um blog e nem e-mail marketing para atrair um maior número de visitas orgânicas, tendo a empresa que investir em mídia paga (facebook e instagram) para conseguir atrair um público considerado baixo comparado com o retorno de suas vendas e geração de novas oportunidades. A organização possui 15 mil seguidores no instagram, 4803 no facebook e o youtube apenas 26 inscritos. A partir desse contexto, pode-se afirmar que a empresa possui pouco engajamento em suas redes sociais e visitação no site corporativo. A empresa possui práticas de SEO para que ela seja encontrada em $1^{\circ}$ lugar no google, porém isso não está sendo feito de maneira eficiente.

Verifica-se então que a empresa necessita de um canal para que seja o centro de seu conteúdo, a proposta é a criação de um blog para publicação de diversos conteúdos para que seus consumidores quando realizarem uma pesquisa no google por exemplo, possam encontrar soluções para seus problemas nesse blog que contará com diversos formatos de posts, tais como: publicações em texto, ebooks em pdf, vídeos curtos e longos, infográficos, manuais, dicas, podcasts e comparativos. Contudo, haverá a necessidade de trabalhar com e-mail marketing para que a empresa esteja sempre em contato com seus clientes, enviando-os conteúdos personalizados, relevantes e interessantes, com isso o resultado será no aumento da interação com sua audiência despertando a atenção do seu público alvo.

\section{CONSIDERAÇÕES FINAIS}

A partir desse estudo, pode-se afirmar que a adoção das estratégias de marketing de conteúdo faz com que as empresas diante de uma concorrência acirrada, tomem impulso para buscarem novas maneiras de atrair a atenção de seu público. As vantagens são inúmeras: facilidade de mensurar os resultados e o retorno sobre o investimento, redução de custos comparados ao marketing tradicional, a média de visitas é 2,2 vezes maior e as oportunidades de se fazer negócios aumentam 3,2 vezes mais do que as empresas 
que não adotam as estratégias de marketing de conteúdo.

Portanto, os objetivos para que a empresa "Pé na Trilha Adventure" adote as estratégias de marketing de conteúdo é fazer com que a ela alcance um número maior de pessoas interessadas na prestação de seus serviços, dessa forma sua brand será mais reconhecida no mercado e maior aumentando as oportunidades de vendas. Por ser uma pequena empresa e não conseguir grandes recursos financeiros para investimento, tais estratégias ajudarão a diminuir consideravelmente os custos mercadológicos. Apesar de possuir uma equipe pequena, isso não justifica a não produção de conteúdos relevantes e úteis para seus consumidores a fim de gerar valor para essas pessoas e consequentemente vencer como uma empresa mais competitiva e obter ótimos resultados.

Enfim, para que a empresa possa de fato alcançar a plenitude em seu mercado, acredita-se que ela deverá aplicar as táticas das estratégias de marketing de conteúdo que irá alavancar as possibilidades de ganhos da empresa, reduzir em $61 \%$ os custos para atrair as verdadeiras oportunidades de negócios e converte-las em vendas.

\section{REFERÊNCIAS}

ASSAD, Nancy. Marketing de conteúdo: como fazer sua empresa decolar no meio digital. São Paulo: Atlas, 2016. 140 p.
em:<http://www.fabiorobertoborges.com/Ebook_I nbound_Marketing_Fabio_Roberto_Borges.pdf $>$. Acesso em: 18. Set. 2017.

FONSECA, Letícia. ContentTrends de 2017. Disponível em: <http://materiais.rockcontent.com/contenttrends>. Acesso em: 25. nov. 2017.

GABRIEL, Martha. Marketing na Era Digital: conceitos, plataformas e estratégias. São Paulo:Novatec Editora, 1. ed. 2010. 424p.

KOTLER, Philip; KARTAJAYA, Hermawan; SETIAWAN, Iwan. Marketing 4.0: do tradicional ao digital. Rio de Janeiro: Editora Sextante, 2017. 208p.

PATEL, Neil. O que é Marketing de Conteúdo: o guia passo a passo.

Disponível em: <https://neilpatel.com/br/o-que-emarketing-de-conteudo-o-guia-passo-a-passo/> . Acesso em 14. Set. 2017.

PEÇANHA, Vitor. Obrigado pelo Marketing: um guia completo de como encantar pessoas e gerar negócios utilizando o marketing de conteúdo. São Paulo: Benvirá, 2017. 238p.

PULLIZI, Joe. Marketing de conteúdo épico: como contar uma história diferente, destacar-se na multidão e conquistar mais clientes com menos marketing. São Paulo: DVS editora, 2016. 333p.

REZ, Rafael. Marketing de Conteúdo: a moeda do século XXI. 1.São Paulo: DVS Editora, 2016. 379 p.

TRAVASSOS, Patrícia; REZ, Rafael; TRAVASSOS, Clovis. Séries sobre BrandedContent. Disponível em: $<\mathrm{http} / / /$ novaescolademarketing.com.br/marketingde-conteudo/branded-content/> . Acesso em: 21. Set.2017.

TURCHI, Sandra R. Estratégias de marketing digital e E-commerce. São Paulo: Atlas, 2012. 208p.

VERGARA, Sylvia Constant. Projetos e Relatórios de Pesquisa em Administração. São Paulo: Atlas, 16. ed.

BORGES, Fabio Roberto. Inbound Marketing. Disponível 